\title{
Hybrid secondary suspension systems
}

\author{
Nader Vahdati ${ }^{\mathrm{a}, *}$ and Mehdi Ahmadian ${ }^{\mathrm{b}}$ \\ a School of Mechanical and Aerospace Engineering, Nanyang Technological University, 50 Nanyang Avenue, \\ 639798, Singapore \\ ${ }^{\mathrm{b}}$ Department of Mechanical Engineering, Virginia Polytechnic Institute, 123 Randolph Hall, Blacksburg, VA \\ 24061, USA
}

Received 26 April 2005

Revised 22 July 2008

\begin{abstract}
Passive fluid mounts are used in the fixed wing applications as engine mounts. The passive fluid mount is placed in between the engine and the fuselage to reduce the cabin's structure- borne noise and vibration generated by the engine.

To investigate the benefits of passive fluid mounts used in conjunction with tuned vibration absorbers (TVA), a simple mathematical model is developed. This mathematical model includes the mathematical model of a passive fluid mount, a TVA, and a spring representing the fuselage structure. The simulation results indicate that when passive fluid mounts are used in conjunction with TVAs, an active suspension system behavior is nearly created.
\end{abstract}

\section{Introduction}

In the past few years, the active suspension system research and development expenditure has risen considerably both in the academia and industry. Some noise and vibration companies have managed to show airplane cabin noise reduction in the order of 15 to $20 \mathrm{dBs}$ using active engine mounts, but despite these successes, very few aerospace companies actually use active engine mounts in their production airplanes and the reason is simply cost.

On the automotive side, active primary suspension systems have been successfully tested since 1970s, but very few cars do use active suspension systems primarily again due to cost. And those automotive companies that do provide active suspension systems to their customers, they do so as an option and not as a standard component.

Since the cost of active suspension systems is high, one may wonder if it is possible to provide nearly the same noise and vibration reduction of an active suspension system, but only using passive systems. The focus of this paper will be on this subject.

The focus of this paper will be on fixed wing applications and the use of passive fluid mounts in conjunction with tuned vibration absorbers, as an engine mounting system.

\section{Aircraft engine vibration}

A typical turbofan jet engine, as shown in Fig. 1, consists of a fan, low and high pressure compressors, and low and high pressure turbines. Basically a jet engine consists of many stationary and rotating blades. In the case of fan, since not all of its rotating blades are exactly identical in size, when the fan rotates, imbalance forces are generated, and this vibration is transmitted to the cabin via the fuselage.

The vibrational energy, from the engine rotary imbalances, causes vibration of the aircraft structure, which can in turn create noise and vibration in the aircraft cabin. This vibrational energy comes from the imbalance of the fan

\footnotetext{
*Corresponding author. Tel.: +1 656790 4332; Fax: +1 656791 1859; E-mail: mnader@ntu.edu.sg.
} 


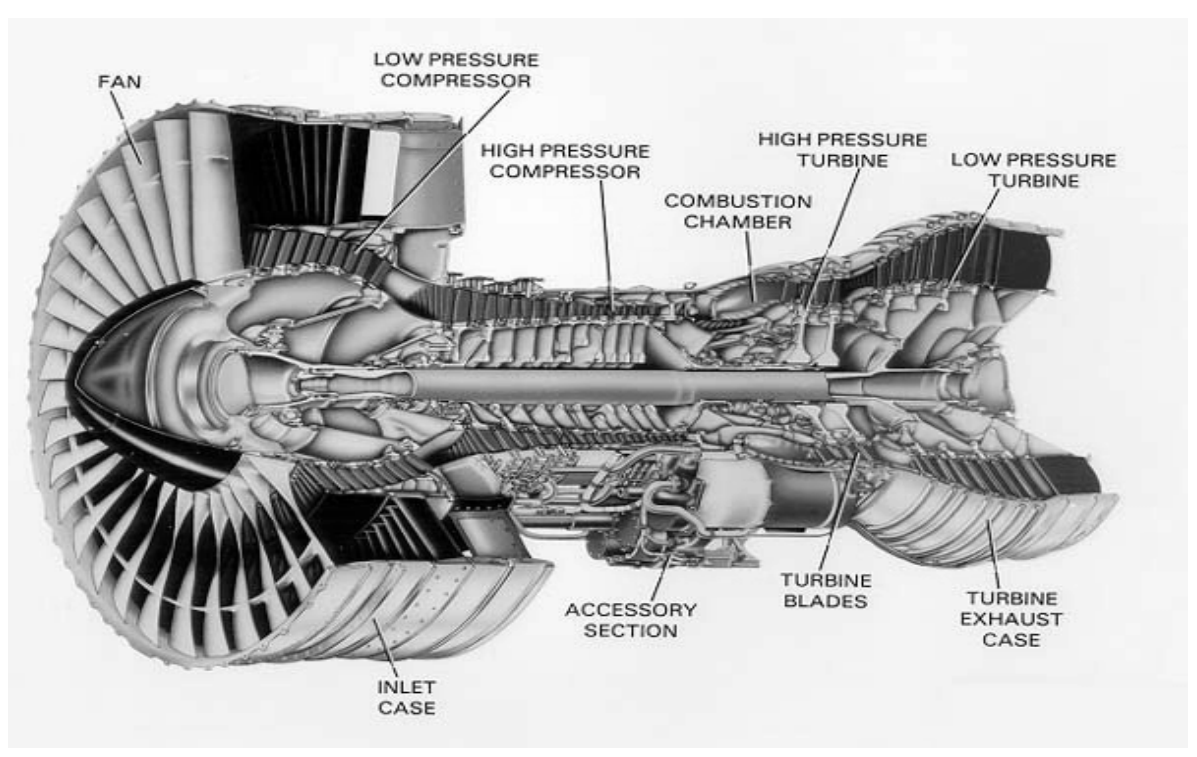

Fig. 1. A typical turbofan jet engine.

and the compressor/turbine. The frequency of the imbalance due to the fan is referred to as the $\mathrm{N}_{1}$ frequency and the frequency of the imbalance due to the compressor/turbine is referred to as the $\mathrm{N}_{2}$ frequency.

Since most of the airplane's flight time is spent at the cruise speed, it makes most sense to reduce the cabin noise and vibration at the cruise speed rather than at the take off or landing speeds.

But at the cruise speed, there are many imbalance (disturbance) excitation frequencies and ideally one wants to isolate the cabin from all the engine imbalance excitation frequencies, but with the current fluid mount technology, the fluid mount notch frequency can only be tuned to one and only one frequency. For example for most turbofan engines the largest imbalance excitation amplitudes normally occur at N1 (engine low speed shaft imbalance excitation frequency) and at N2 (engine high speed shaft imbalance excitation frequency), but since the current fluid mount design technology only offers isolation at one frequency, a fluid mount designer has no choice but to choose isolation at $\mathrm{N} 1$ or at $\mathrm{N} 2$ during cruise.

\section{Various vibration and noise isolators}

There are various different ways of reducing cabin noise and vibration in fixed wing applications. Rubber mounts, passive fluid mounts, adaptive fluid mounts, and active mounts are all examples of different types of vibration isolators capable of reducing cabin noise and vibration.

\section{Elastomeric mounts}

Rubber-to- metal (RTM) bonded mounts have been used in fixed wing applications for many years to decrease engine noise and vibration transmitted to the cabin. If we assume the jet engine and the fuselage structure as rigid bodies, then the engine on its mounting system (see Fig. 2) will have six natural frequencies. If the engine operates above the six natural frequencies, the cabin will be isolated from the engine vibration. To keep the six natural frequencies low, the rubber mounts need to be soft. But making the rubber mounts soft cause excessive engine motion under thrust, maneuver, and blade-out loads.

So, design tradeoffs on the mount stiffnesses [1] have to be made to meet the goals of a high static stiffness for limiting engine motion under thrust, maneuver, and blade-out loads, and a low dynamic stiffness for noise and vibration isolation at operating frequencies. The RTM bonded mounts, which have relatively constant dynamic stiffness, is incapable of providing high static stiffness and low dynamic stiffness at higher frequencies. 


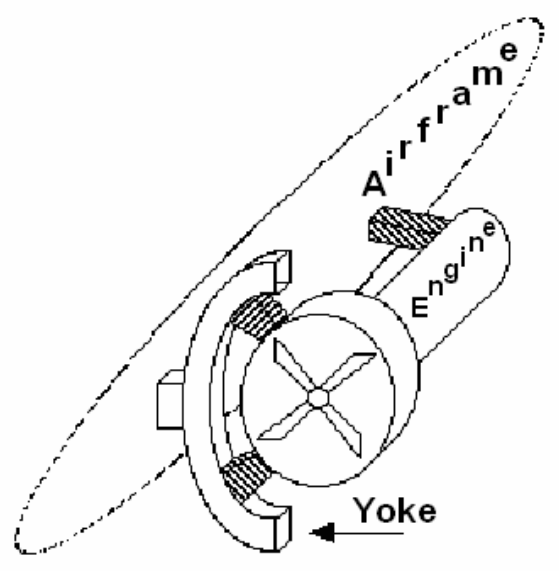

Fig. 2. A jet engine connected to the airframe, via three rubber mounts.

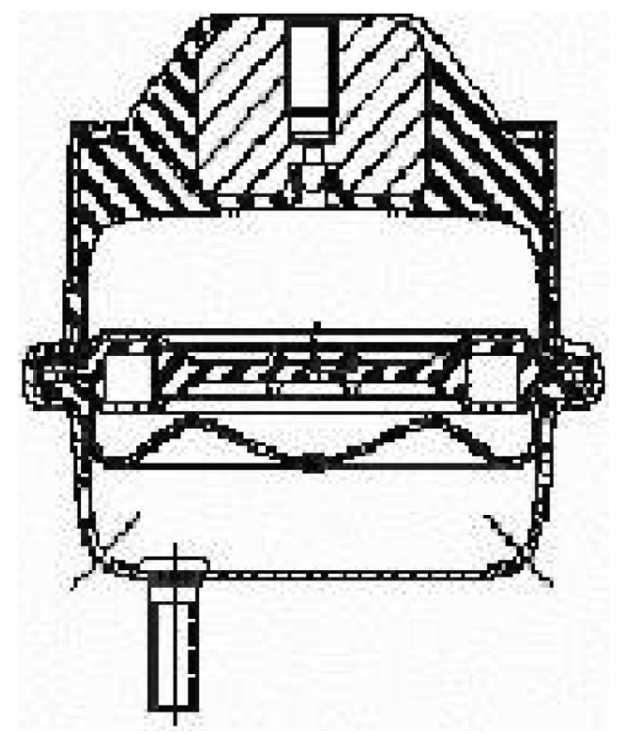

Fig. 3. A single pumper passive fluid mount.

\section{Passive fluid mounts}

The passive fluid mount technology is an improvement because it allows for a relatively high static stiffness, but low dynamic stiffness at a specific frequency by using the vibration absorber effect of the oscillating fluid in the mount. A passive fluid mount [2-5], as shown in Figs 3 and 4, consists of fluid contained in two elastomeric cavities, which are connected together through an inertia track. The two cavities are mechanically driven by the oscillating input motion to the mount.

The oscillating fluid results in a tuned mass absorber effect, which reduces the dynamic stiffness of the mount at the mass tuned frequency. With the right combination of fluid mount parameters, such as the inertia track length, cross-sectional area, and stiffnesses, vibration and noise isolation is provided at a given desired frequency coined "notch frequency". Figure 5 shows a typical dynamic stiffness of a passive fluid mount. Figure 5 shows that the dynamic stiffness of the fluid mount at low frequencies is high; therefore, limiting engine motion. At the notch frequency the dynamic stiffness is very low; therefore providing cabin noise and vibration isolation. At higher 


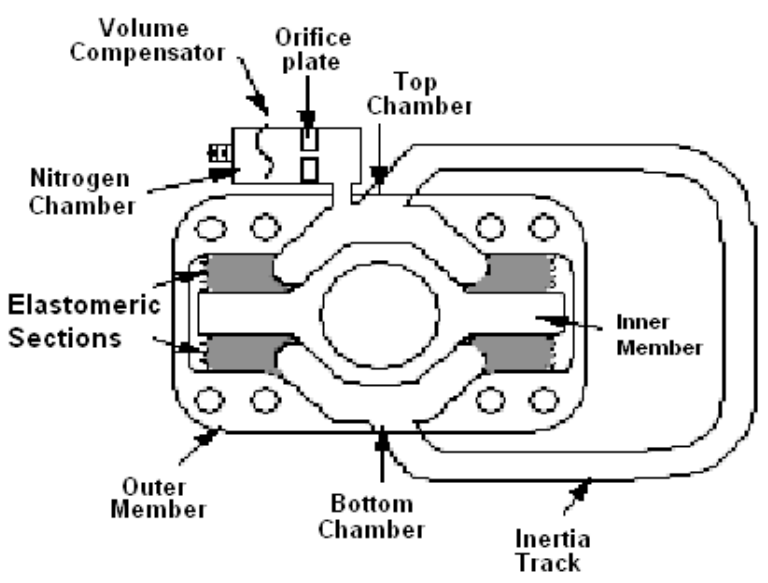

Fig. 4. A double pumper passive fluid mount.

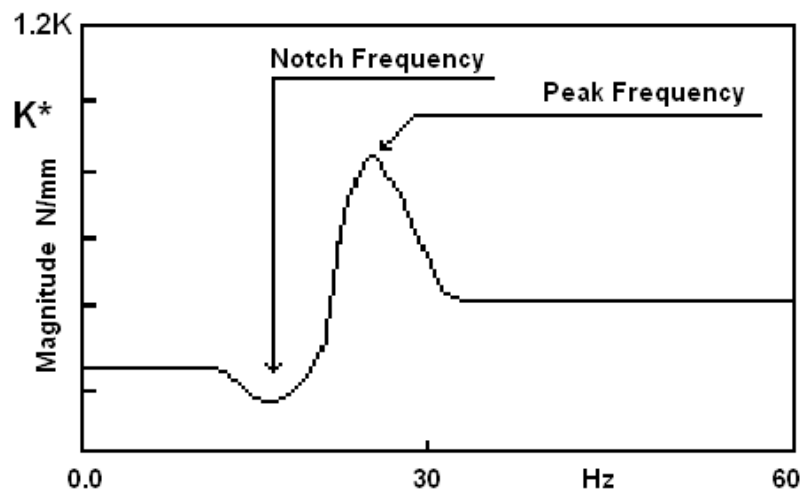

Fig. 5. A typical passive fluid mount dynamic stiffness.

frequencies closer to the peak frequency, the dynamic stiffness increases and as a result cabin noise and vibration increases too. For lowest cabin noise and vibration levels, one needs to operate close to the notch frequency.

There are two types of fluid mounts: single pumper fluid mounts [2-4], see Fig. 3, and double pumper fluid mounts [5,6], see Fig. 4. In a single pumper fluid mount, only one of the cavities does the pumping; whereas in a double pumper fluid mount, both cavities move or pump fluid. The focus of this paper is on double pumper fluid mounts in conjunction with a TVA.

\section{Adaptive suspension systems}

With passive fluid mounts, a low dynamic stiffness is obtained at one specific frequency; therefore, providing cabin noise and vibration isolation at a narrow frequency band.

With adaptive fluid mounts [6,7], the location of the notch frequency can be varied by varying the fluid mount parameters in real-time. This allows the isolation region to vary depending upon where the engine operating frequency is. See Fig. 6.

Some of the fluid mount parameters that are often used to vary notch frequency in real-time are inertia track length or diameter [7], top or bottom chamber volumetric stiffness [7], fluid apparent viscosity [8], or rubber vertical stiffness $[9,10]$. 


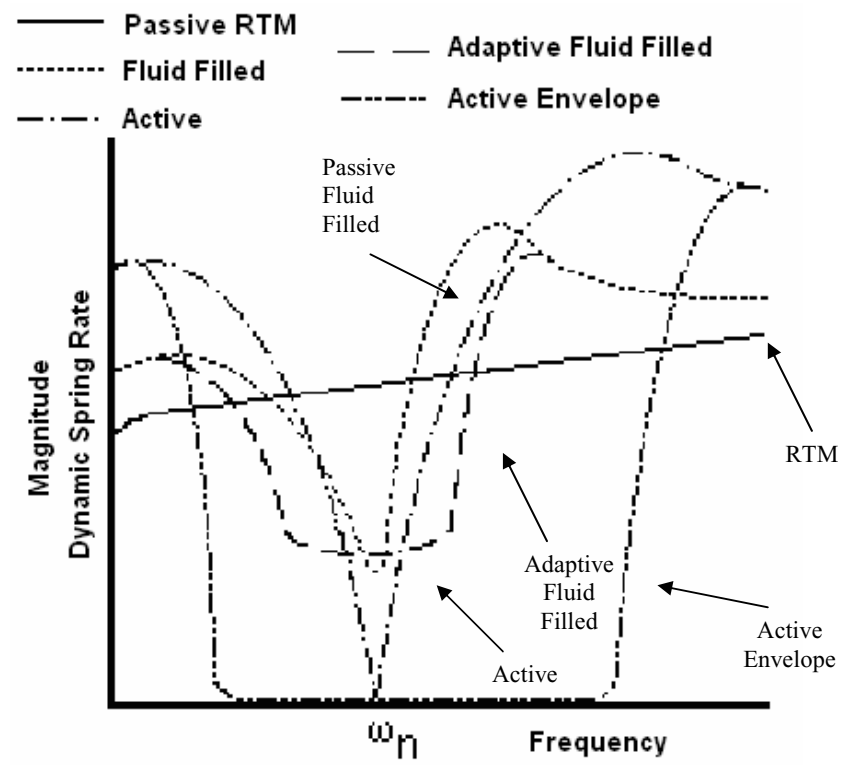

Fig. 6. Dynamic stiffness for various vibration isolators.

Changing inertia track length and diameter in real-time is some what difficult since it requires a variable length and/or variable diameter inertia track. In [7], it was explained that changing inertia track length and diameter not only affects fluid inertia but also affects inertia track flow losses. So, increasing inertia track length or decreasing diameter, increases flow losses and an increase in the flow losses has adverse effect on the fluid mount notch. So, in general, it is not always desirable to change inertia track length or diameter in real-time.

Reference [8] has used MR-fluids to change the apparent viscosity of the working fluid or restrict the flow of the working fluid through inertia track or tracks. But this method has some drawbacks of its own and the drawback is the increase in fluid damping which can cause the notch depth to be reduced.

References $[9,10]$ have used MR-fluids to create a variable stiffness elastomer. So by applying magnetic field on the MR-fluids, the rubber vertical stiffness changes and as a result so does the notch. But when magnetic field is increased, the rubber damping also goes up and this change in damping, if not controlled, can result in reduction of the notch frequency depth.

In reference [7], detailed discussions have been presented on which fluid mount parameters are easiest to vary in real-time, so we refer the readers to reference [7] for more detailed discussions.

Adaptive fluid mounts, if properly designed, are better than traditional passive fluid mounts but they are costlier than passive vibration isolators since they involve some controllable mechanism, a sensor, and a controller. But adaptive fluid mounts are cheaper than active suspension systems since no actuators are used in the adaptive fluid mounts.

\section{Active suspension systems}

Active suspension systems (or isolators) on the other hand, not only provide wide frequency range of vibration and noise isolation, they also provide the lowest cabin noise and vibration levels even in the presence of flanking paths (hoses, links, etc.) [11,12]. See Fig. 6.

In the case of an active suspension system, a compliant element such as a rubber mount or a fluid mount is used in conjunction with an actuator, as shown in Fig. 7. The actuator of Fig. 7 controls the pressure of the fluid chambers; therefore, controls the dynamic stiffness of the mount. The actuator provides the ability of isolating multiple tonal disturbances, and tracking tonal disturbances in a wide frequency range. If one were supposed to compare passive elastomeric, passive fluid, adaptive fluid, and active mounts, Fig. 6 [1] would result. In this figure, we can see that the 


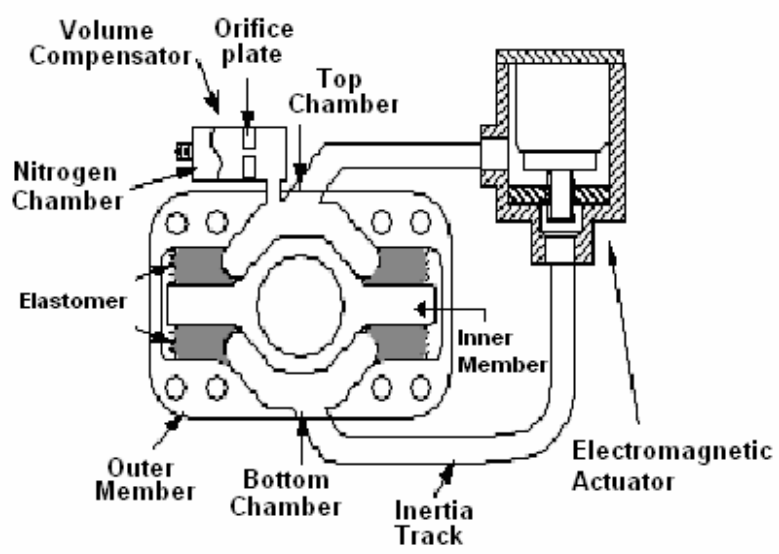

Fig. 7. A double pumper active fluid mount.

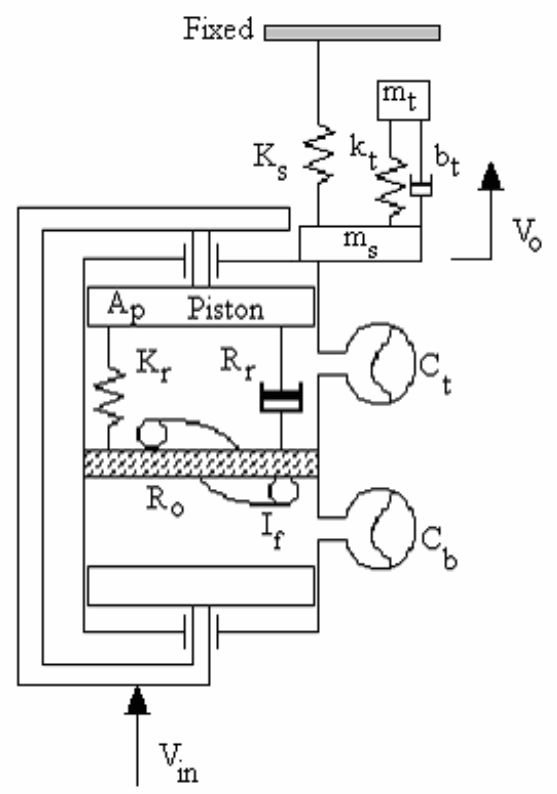

Fig. 8. Physical model considered for this paper.

active suspension system provides almost zero dynamic stiffness in a wide frequency band, when other suspension systems do not. Low dynamic stiffness translates into reduction of cabin noise and vibration, but there is a price to pay, and that is the higher cost of the active systems.

From Fig. 6 we learn that an ideal suspension system is one that behaves like the active suspension system. The passive suspension systems are cheap but they do not provide noise and vibration reduction as well as the active suspension systems. The question to ask here would be: "Can one combine several different passive suspension systems to get the active suspension system behavior?" The answer is of course no. The active suspension system can provide cabin noise and vibration isolation even in the presence of flanking paths where a totally passive suspension system cannot. One may be able to get close to active suspension system behavior but never the same. In this paper, it will be shown that a combination of a passive fluid mount used in conjunction with a tuned vibration absorber (TVA) can nearly behave like the active suspension system. 


\section{Tuned vibration absorbers (TVAs)}

A simple tuned vibration absorber (TVA) $[13,14]$ consists of a mass, a compliant element, and a damping element. TVAs are called tuned absorbers since they are tuned to a particular frequency at which the mass goes to resonance. It is at this frequency where the TVA absorbs the vibrational energy. TVAs are normally used to reduce vibrations of constant RPM machines that are excessively vibrating. Once the TVA is installed on the vibrating machinery, the TVA goes to resonance instead of the main mass and as a result the motion and the vibration of the main mass is reduced.

\section{Passive hybrid suspension systems}

A passive hybrid suspension system, being discussed in this paper, consists of a passive double pumper fluid mount used in conjunction with a tuned vibration absorber. Extensive literature review was conducted and literature review indicates that no one has combined a tuned vibration absorber with a passive fluid mount before this paper. Many papers have been published on the subject of fluid mounts (or hydraulic mounts) and tuned vibration absorbers but never combined.

To show the benefits of such a suspension system, a simple model, shown in Fig. 8, will be considered. Figure 8 shows a double pumper fluid mount physical model subject to an input velocity $\mathrm{V}_{\text {in }}$ induced by the engine. At the other end of the passive fluid mount is a single TVA represented by a mass $\mathrm{m}_{t}$, a stiffness $\mathrm{k}_{t}$, and a damper $\mathrm{b}_{t}$. The spring $\mathrm{K}_{s}$, and mass $\mathrm{m}_{s}$ represent the fuselage structural mass and stiffness. In Fig. 2, an engine was shown to be connected to an airframe via three engine mounts. The model of Fig. 8 represents one of the engine mounts.

The passive fluid mount parameters are defined as,
$\mathrm{K}_{r} \quad$ axial stiffness of the load carrying rubber
$\mathrm{R}_{r} \quad$ hysteretic damping of the rubber
$\mathrm{A}_{p} \quad$ effective pumping (or piston) area
$\mathrm{I}_{f} \quad$ inertia track fluid inertia
$\mathrm{R}_{o} \quad$ inertia track flow losses
$\mathrm{C}_{t} \quad$ top fluid chamber volume compliance
$\mathrm{C}_{b} \quad$ bottom fluid chamber volume compliance

For better definition of these parameters, see reference [5]. Bond Graph modeling technique [15] is used to develop the equations of the motion for the physical model of Fig. 8. The bond graph model of Fig. 8 is shown in Fig. 9.

In the bond graph model of Fig. 9, it is assumed that the pressure drop in the inertia track is a linear function of flow rate, the damping of the rubber in the bulge direction is assumed negligible, and the stiffness of the rubber is assumed constant and not a function of frequency and strain. In general, when passive fluid mounts are designed, great efforts are made to reduce flow losses in the inertia track, and to choose low damped elastomers. So, neglecting rubber damping in the bulge direction, and assuming rubber stiffnesses as constants are reasonable assumptions. As far as flow losses in the inertia track is concerned, the pressure drop and the flow rate have a nonlinear relationship and in most cases should be modeled as such. But here in this paper, we intend to show the benefits of TVAs used in conjunction with passive fluid mounts, and as long as inertia track flow losses are kept low, it is not important if there is a nonlinear or a linear relationship between pressure drop and flow rate. So, the state space equations are obtained from the bond graph model of Fig. 9, as follows:

$$
\left[\begin{array}{l}
\dot{q}_{4} \\
\dot{q}_{8} \\
\dot{P}_{11} \\
\dot{q}_{13} \\
\dot{P}_{16} \\
\dot{q}_{17} \\
\dot{q}_{19} \\
\dot{P}_{20}
\end{array}\right]=\left[\begin{array}{llllllll}
0 & 0 & 0 & 0 & -\frac{1}{I_{16}} & 0 & 0 & 0 \\
0 & 0 & -\frac{1}{I_{11}} & 0 & -\frac{A_{p}}{I_{16}} & 0 & 0 & 0 \\
0 & \frac{1}{C_{8}}-\frac{R_{10}}{I_{11}}-\frac{1}{C_{13}} 0 & 0 & 0 & 0 \\
0 & 0 & \frac{1}{I_{11}} & 0 & \frac{A_{p}}{I_{16}} & 0 & 0 & 0 \\
\frac{1}{C_{4}} & \frac{A_{p}}{C_{8}} & 0 & -\frac{A_{p}}{C_{13}}-\frac{\left(R_{5}+R_{22}\right)}{I_{16}} & -\frac{1}{C_{17}}-\frac{1}{C_{19}} & \frac{R_{22}}{I_{20}} \\
0 & 0 & 0 & 0 & \frac{1}{I_{16}} & 0 & 0 & 0 \\
0 & 0 & 0 & 0 & \frac{1}{I_{16}} & 0 & 0 & -\frac{1}{I_{20}} \\
0 & 0 & 0 & 0 & \frac{R_{22}}{I_{16}} & 0 & \frac{1}{C_{19}} & -\frac{R_{22}}{I_{20}}
\end{array}\right]\left[\begin{array}{l}
q_{4} \\
q_{8} \\
P_{11} \\
q_{13} \\
P_{16} \\
q_{17} \\
q_{19} \\
P_{20}
\end{array}\right]+\left[\begin{array}{l}
1 \\
A_{p} \\
0 \\
-A_{p} \\
R_{5} \\
0 \\
0 \\
0
\end{array}\right] V_{i n}
$$




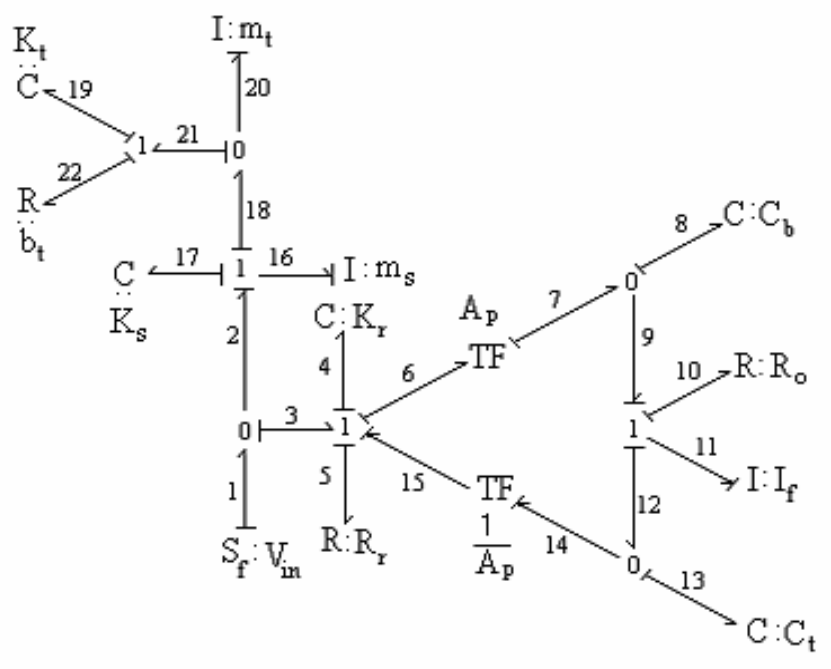

Fig. 9. Bond graph model of Fig. 8.

where $\mathrm{q}_{4}, \mathrm{q}_{8}, \mathrm{p}_{11}, \mathrm{q}_{13}, \mathrm{p}_{16}, \mathrm{q}_{17}, \mathrm{q}_{19}$, and $\mathrm{p}_{20}$ are the state variables. The state variables are defined as follows:

$\mathrm{q}_{4} \quad$ Relative motion across the spring $\mathrm{K}_{r}$

$\mathrm{q}_{8} \quad$ Change in the volume of the bottom fluid chamber

$\mathrm{p}_{11} \quad$ The momentum of the mass of the fluid in the inertia track

$\mathrm{q}_{13} \quad$ Change in the volume of the top fluid chamber

$\mathrm{p}_{16} \quad$ Momentum of the mass $\mathrm{m}_{s}$

$\mathrm{q}_{17} \quad$ Relative motion across the spring $\mathrm{K}_{s}$

$\mathrm{q}_{19} \quad$ Relative motion across the spring $\mathbf{K}_{t}$

$\mathrm{p}_{20} \quad$ Momentum of the TVA mass $\mathrm{m}_{t}$

The output equation (cabin transmitted force) is equal to,

$$
e_{17}=\frac{q_{17}}{C_{17}}=K_{s} q_{17}
$$

To isolate cabin from the engine structure-borne noise and vibration, we will need the transmitted force to approach zero. In the next following sections, the parameter $\frac{e_{17}}{X_{i n}}$ (transmitted force divided by input motion) will be plotted versus frequency for several different vibration isolators. We will refer to this ratio as the dynamic stiffness. To have low transmitted force, we will need very low dynamic stiffness $\left(\frac{e_{17}}{X_{i n}}\right)$ at the cruise condition.

\section{Fluid mount simulation parameters}

The following fluid mount parameters were used in the simulations:

$\mathrm{K}_{r} \quad$ Fluid mount rubber axial stiffness, $8.05 \mathrm{e} 6 \mathrm{~N} / \mathrm{m}(46,000 \mathrm{lb} / \mathrm{in})$

$\operatorname{Tan} \delta \quad$ Rubber damping, $\tan \delta=\mathrm{G}^{\prime \prime} / \mathrm{G}^{\prime}, 0.1$ (G', and G' are real and Imag. Shear moduli)

$\mathrm{R}_{r} \quad$ Equivalent viscous damping of the rubber, $\left(\operatorname{Tan} \delta * \mathrm{~K}_{r}\right) / \omega$

$\mathrm{C}_{b} \quad$ Top chamber volume compliance, $1.5 \mathrm{E}-13 \mathrm{~m}^{\wedge} 5 / \mathrm{N}(6.33 \mathrm{E}-5 \mathrm{in} 5 / \mathrm{lb})$

$\mathrm{C}_{t} \quad$ Bottom Chamber volume compliance, 3.17E-13 $\mathrm{m}^{\wedge} 5 / \mathrm{N}(13.33-5$ in^5/lb)

$\mathrm{R}_{o} \quad$ Flow Losses in the inertia track, $0<\mathrm{R}_{o}<0.1 \mathrm{e} 9 \mathrm{~N}$-s/m $(0$ to $0.25 \mathrm{lb}$-s/in`5)

$\mathrm{I}_{f} \quad$ Inertia track fluid inertia, $\frac{\rho L}{A_{t}}, 62,867 \mathrm{~N}-\mathrm{S}^{2} / \mathrm{m}^{5}\left(0.15 \mathrm{E}-3 \mathrm{lbf}-\mathrm{s}^{2} / \mathrm{in}^{5}\right)$

$\rho \quad$ Fluid density, $\mathrm{kg} / \mathrm{m} \wedge 3$

$\mathrm{L} \quad$ Inertia track length, $\mathrm{m}$ 


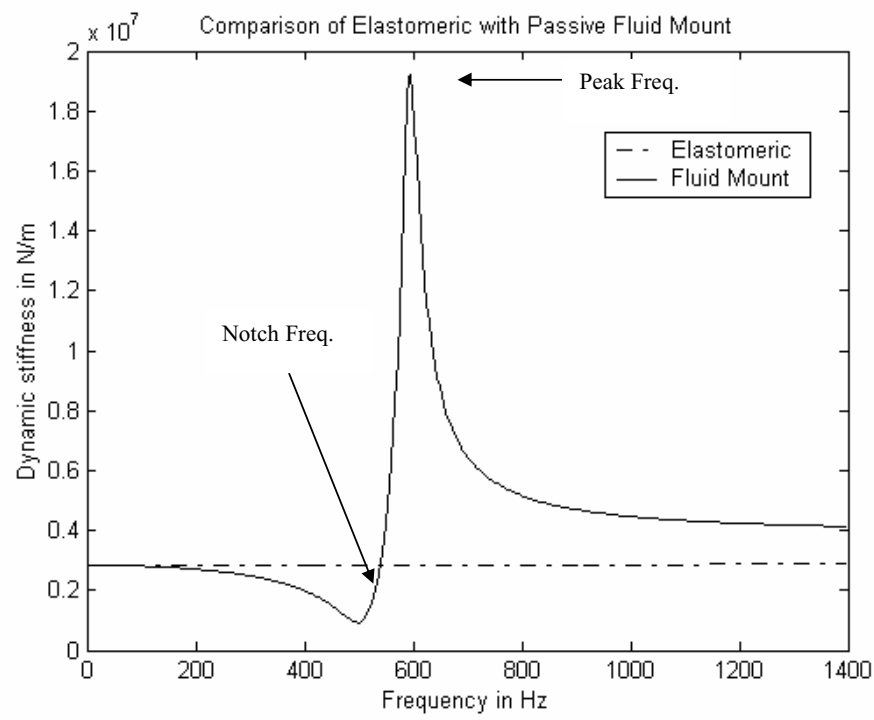

Fig. 10. A Rubber Mount (dashed) versus a Passive Fluid Mount (solid).
$\mathrm{A}_{p} \quad$ Effective piston area, $0.00167 \mathrm{~m}^{\wedge} 2\left(2.6 \mathrm{in}^{\wedge} 2\right)$
$\mathrm{A}_{t} \quad$ Inertia track cross-sectional area, $\mathrm{m}^{\wedge} 2$
$\omega \quad$ Circular Frequency, $\mathrm{rad} / \mathrm{s}$
$\mathrm{N}_{1} \quad$ At cruise condition, $500 \mathrm{~Hz}$
$\mathrm{N}_{2} \quad$ At cruise condition, $950 \mathrm{~Hz}$
The fuselage structure was assumed to have a stiffness of:
$\mathrm{K}_{s} \quad$ Structural stiffness, $4.378 \mathrm{E} 6 \mathrm{~N} / \mathrm{m}(25,000 \mathrm{lb} / \mathrm{in})$

\section{Rubber mounts versus fluid mounts}

In the first simulation we have an elastomeric mount with a stiffness of $\mathrm{K}_{r}=8.05 \mathrm{E} 6 \mathrm{~N} / \mathrm{m}(46,000 \mathrm{lb} / \mathrm{in})$ in series with a structure with a stiffness of $\mathrm{K}_{s}=4.378 \mathrm{E} 6 \mathrm{~N} / \mathrm{m}(25,000 \mathrm{lb} / \mathrm{in})$. The mass of the structure, $\mathrm{m}_{s}$, is assumed very low meaning its natural frequency is very high, well above $950 \mathrm{~Hz}$. This structural stiffness represents the stiffness of a small business jet fuselage/mounting bracket.

In the second simulation, a passive fluid mount is designed for the cruise N1 frequency, which is $500 \mathrm{~Hz}$, with an initial stiffness of $8.05 \mathrm{E} 6 \mathrm{~N} / \mathrm{m}(46,000 \mathrm{lb} / \mathrm{in})$ in series with the same structure. To create a $500 \mathrm{~Hz}$ notch passive fluid mount, all the above fluid mount parameters were used except the fluid inertia was set to $194,029 \mathrm{~N}-\mathrm{s}^{2} / \mathrm{m}^{5}$ $\left(0.463 \mathrm{E}-3 \mathrm{lbf}-\mathrm{s}^{2} / \mathrm{in}^{5}\right)$. Figure 10 shows the dynamic stiffness $\left(\frac{e_{17}}{X_{i n}}\right)$ of the two isolators versus frequency. Notice that the dynamic stiffness of the fluid mount case approaches zero around $500 \mathrm{~Hz}$. Cabin vibration and noise isolation is achieved at $500 \mathrm{~Hz}$. But at higher frequencies, the dynamic stiffness increases; therefore, aircraft cabin noise and vibration increases if the engine was to operate above $500 \mathrm{~Hz}$ or if tonal disturbances are present at higher frequencies. From Fig. 10, it is noticed that the fluid mount notch frequency appears first and then the peak frequency. This important property will be successfully used later.

It is important to mention that the fluid mount notch frequency can be designed for any frequency. Normally, the notch is designed for either the $\mathrm{N} 1$ or the $\mathrm{N} 2$ frequencies at the cruise condition.

Higher the notch frequency is, higher the inertia track flow losses will be. So for applications where the fluid mount's notch frequency needs to be designed for N2 frequency, careful design of the inertia track will be needed to minimize the inertia track flow losses. 


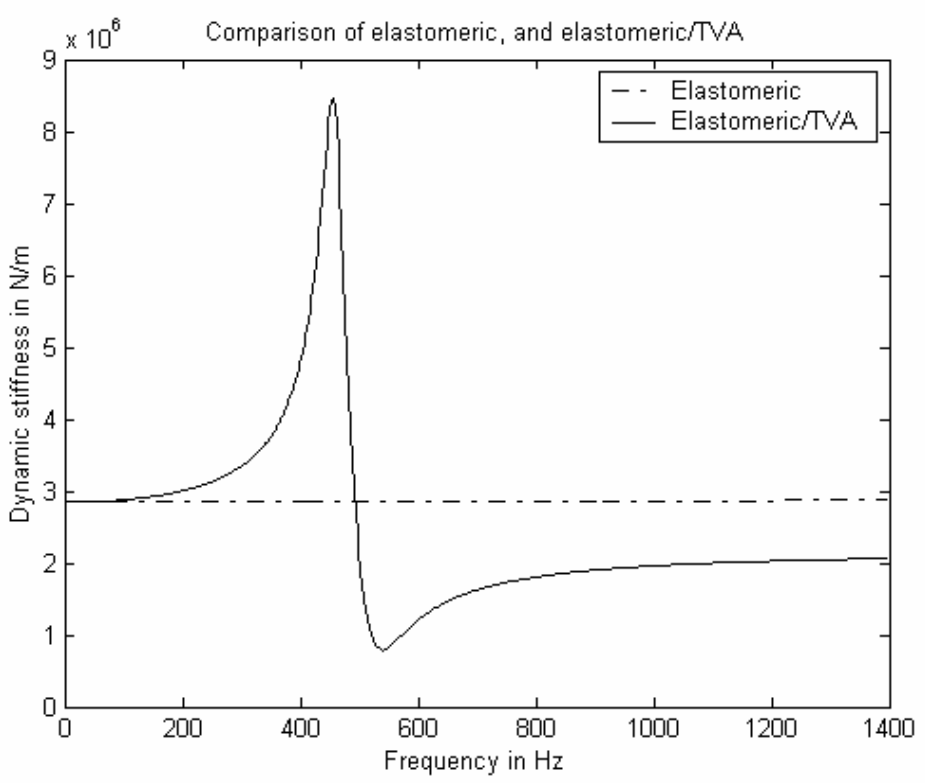

(a)

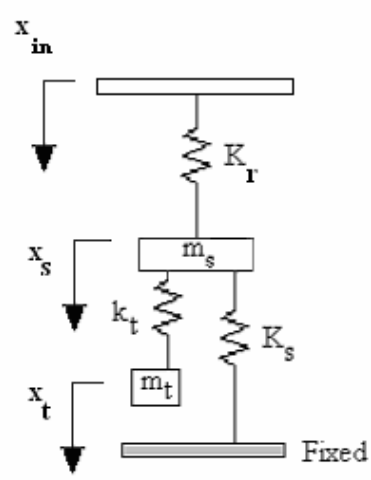

(b)

Fig. 11. (a) Rubber mount (dashed) versus Rubber Mount/TVA (solid). (b) Simplified model of a rubber mount, fuselage structure and TVA.

\section{Rubber mount with a TVA}

Now we are going to simulate a rubber mount with a stiffness of $8.05 \mathrm{E} 6 \mathrm{~N} / \mathrm{m}(46,000 \mathrm{lb} / \mathrm{in})$ in conjunction with a $500 \mathrm{~Hz}$ TVA $\left(\mathrm{K}_{t v a}=23000 \mathrm{lbf} / \mathrm{in}, \mathrm{w}_{t v a}=0.8 \mathrm{lbf}\right)$ attached to a structure with a stiffness of $4.378 \mathrm{E} 6 \mathrm{~N} / \mathrm{m}(25,000$ $\mathrm{lb} / \mathrm{in})$ and same structural mass. Figure 11a shows the dynamic stiffness $\left(\frac{e_{17}}{X_{i n}}\right)$ of a rubber mount/TVA system in comparison with an elastomeric mount.

Notice that with the rubber mount/TVA system, the peak frequency appears first and then the notch. To explain why the TVA peak frequency occurring first and then the notch, the simple model of Fig. 11b is used. In this model, $\mathrm{K}_{r}$, represents the elastomer stiffness, $\mathrm{K}_{s}$, and $\mathrm{m}_{s}$, the fuselage stiffness and mass, and $\mathrm{K}_{t}$, and $\mathrm{m}_{t}$, the TVA stiffness and mass. If we assume rubber damping to be negligible and the structure mass, $\mathrm{m}_{s}$, being small, the following transfer function can be obtained:

$$
\|K\|=\frac{\text { Transmitted Force }}{\text { Input Displacment }}=\frac{K_{s} K_{r}\left(K_{t}-m_{t} \omega^{2}\right)}{K_{t}\left(K_{s}+K_{r}\right)-m_{t} \omega^{2}\left(K_{r}+K_{s}+K_{t}\right)}
$$


The notch frequency takes place when the numerator is zero, and the peak when the denominator is zero. So, the notch frequency is then equal to:

$$
f_{\text {notch }}=\frac{1}{2} \sqrt{\frac{K_{t}}{m_{t}}}
$$

And the peak occurs at:

$$
f_{\text {peak }}=\frac{1}{2} \sqrt{\frac{K_{t}}{m_{t}}} \sqrt{\frac{K_{s}+K_{r}}{K_{r}+K_{s}+K_{t}}}
$$

If the peak frequency equation is re-written in terms of the notch frequency, the following equation results:

$$
f_{\text {peak }}=f_{\text {notch }} \sqrt{\frac{K_{s}+K_{r}}{K_{r}+K_{s}+K_{t}}}
$$

The value of the square root expression is less than 1 . This implies that the peak frequency occurs first and then the notch.

Figure 11a reveals that a rubber mount with a TVA provides better cabin noise and vibration reduction than a pure rubber mount particularly at higher frequencies due to a lower dynamic stiffness. For this paper, the N1 frequency at the cruise condition is assumed to be about $500 \mathrm{~Hz}$. At $500 \mathrm{~Hz}$, we provide very good noise and vibration isolation, and at higher frequencies, if there are other tonal disturbances such as N2 and harmonics of N1 and N2, we would get lower cabin noise and vibration than using pure rubber mount.

If one closely looks at Figs 10 and 11a, an interesting idea can be observed. Why not design a TVA tuned for N1 or few $\mathrm{Hz}$ lower and design a fluid mount tuned for $\mathrm{N} 2$ or few $\mathrm{Hz}$ higher.

\section{Fluid mount/TVA system}

In this simulation, a fluid mount is designed to have a notch at $950 \mathrm{~Hz}$ ( $\mathrm{N} 2$ at cruise condition), and a TVA designed for $500 \mathrm{~Hz}$ (N1 at cruise condition). The same structural mass and stiffness was used. Figure 12 shows that a combination of a fluid mount and a TVA is resulting in a nearly active suspension system behavior. As fluid losses and rubber damping are minimized, the fluid mount/TVA system behavior approaches that of the active systems (compare Fig. 6 with Fig. 12).

\section{Parametric studies (impact of TVA mass, flow losses, and structure mass)}

Figure 13 shows the impact of the TVA's mass on the dynamic stiffness. The mass ratio (TVA mass divided by Structure mass) was varied from 2 to 8 . Figure 13 shows that as the TVA mass is increased, better noise and vibration isolation is achieved due to decrease in dynamic stiffness. Figure 13 also shows that when TVA mass is increased, wider noise and vibration isolation frequency band is achieved.

Figure 14 shows that as flow losses in the inertia track increase, there is an increase in dynamic stiffness at the notch frequency; therefore, an increase in cabin noise and vibration, but little change in isolation frequency band is observed.

In all the above simulations, it was assumed that the mounting bracket that connects the engine to the fuselage has no resonance in the range of 500 to $950 \mathrm{~Hz}$. If it does, Fig. 15 results. Figure 15 indicates that if the mounting bracket is having any resonances in the range of 500 to $950 \mathrm{~Hz}$, the cabin noise and vibration isolation will be affected. In such cases, one could increase the TVA mass and bring back the fluid mount peak frequency to a higher frequency as we did in Fig. 13. Figure 16 shows a comparison of rubber mount, fluid mount, rubber mount/TVA, and fluid mount/TVA dynamic stiffnesses. Fluid mount/TVA hybrid suspension system clearly is better than other passive isolators. 


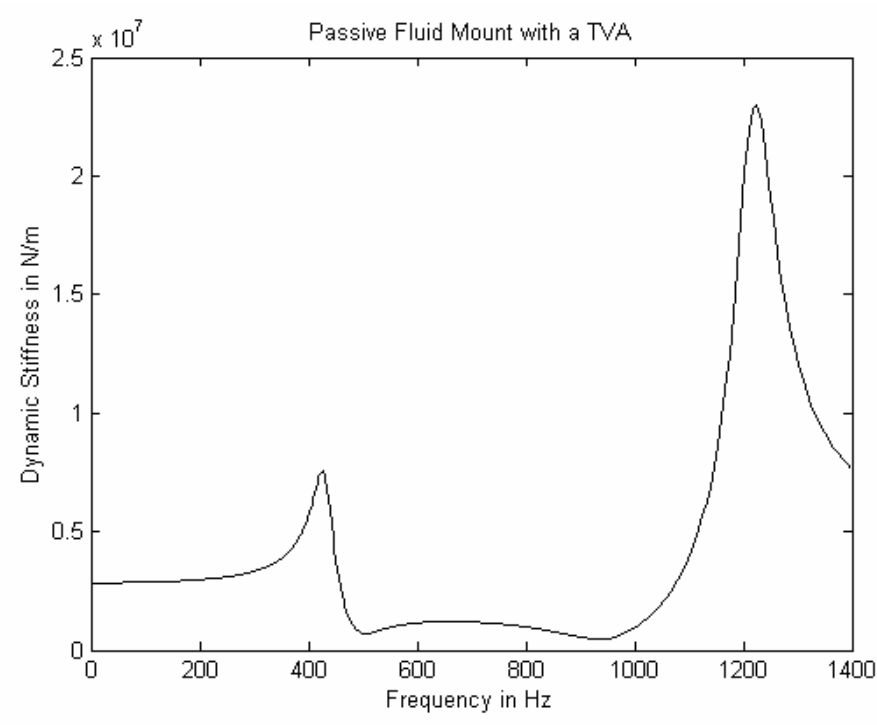

Fig. 12. Passive fluid Mount/TVA suspension system.

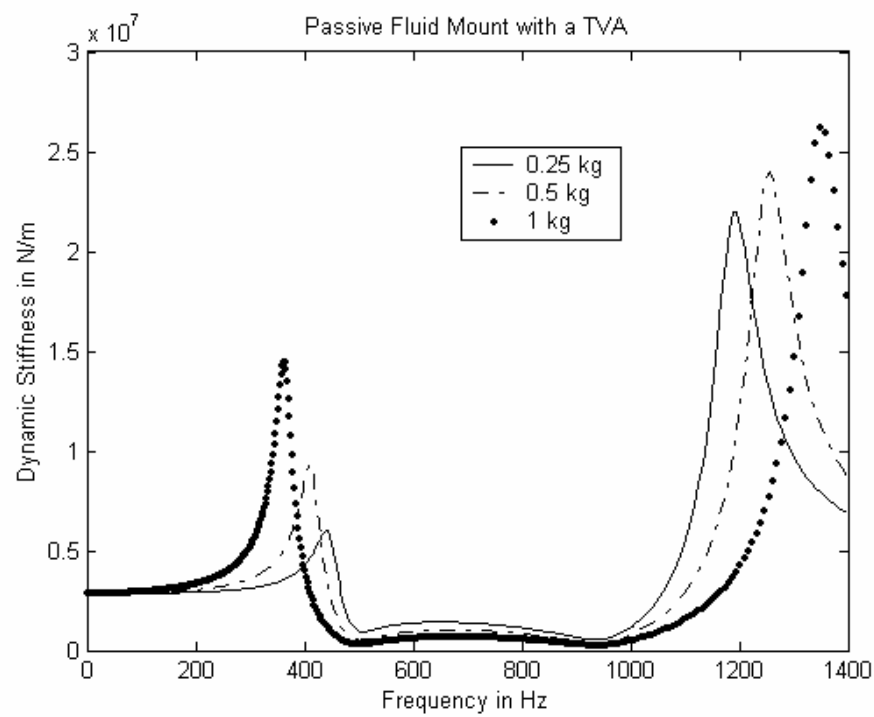

Fig. 13. Effect of TVA mass on dynamic stiffness.

\section{Conclusions}

This project started with a design of a passive fluid mount for a business jet that had a soft fuselage structure. One of the disadvantages of a soft structure with a fluid mount installed on it, is that it causes the notch frequency of the fluid mount to move from what it was designed for. In general, when one designs a fluid mount for a new airplane, the structural stiffnesses are unknown or the stiffnesses are from some finite element model which cannot be completely trusted. So, once the fluid mount is designed and the airplane is manufactured, it is possible that the airplane fuselage may end up to be soft; therefore, causing the notch frequency to move from its intended designed frequency. Once the notch frequency is moved from its intended designed frequency, the noise and vibration isolation levels increase. 


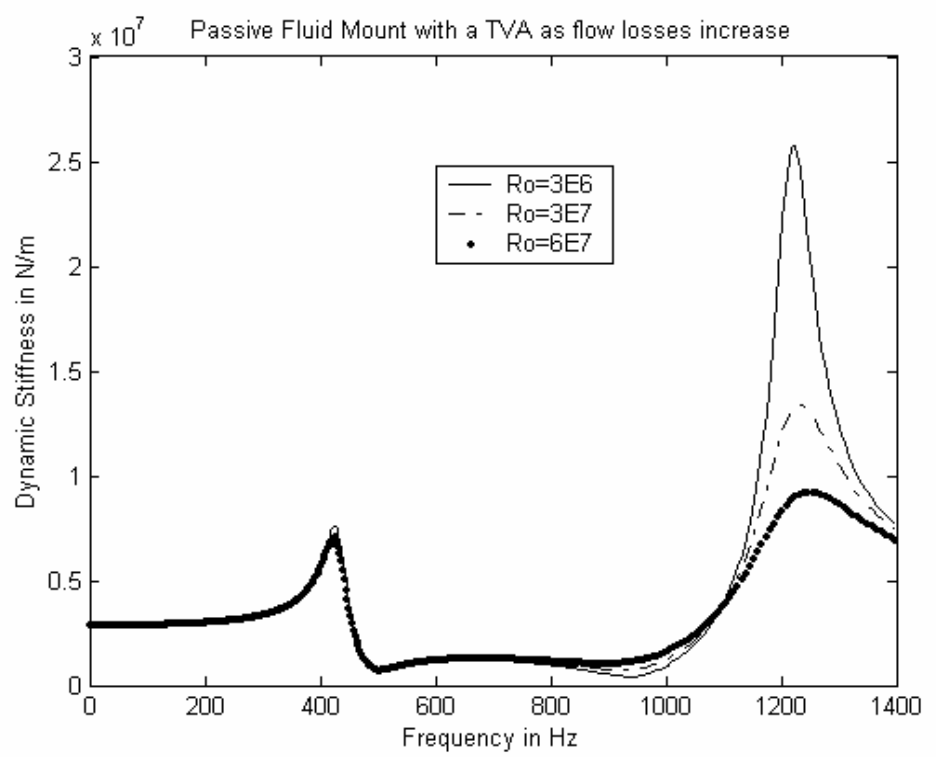

Fig. 14. Dynamic stiffness as a function of damping (fluid losses).

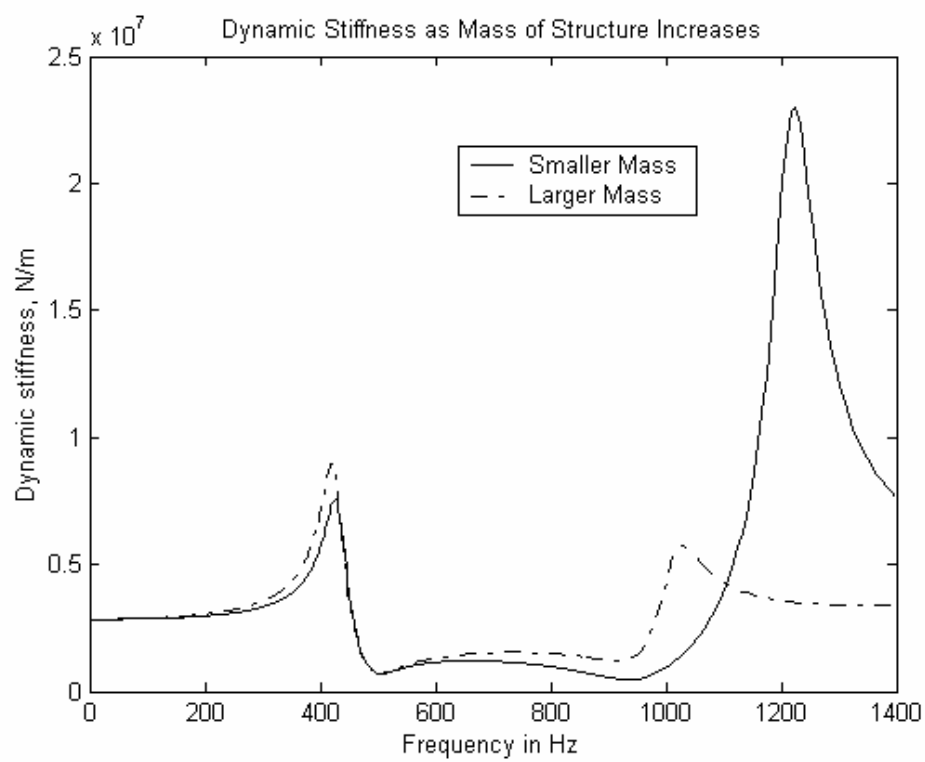

Fig. 15. Dynamic stiffness as structure mass is increased.

So, TVAs were employed in this project to stiffen up the fuselage structure, but as a result of this project, passive hybrid suspension systems were discovered.

It was shown in this paper that it is possible to combine two passive systems and create nearly an active system behavior. The authors show that with a combination of a passive fluid mount designed for N2 cruise condition and a tuned vibration absorber (TVA) designed for N1 cruise condition, the dynamic stiffness of this passive hybrid suspension system nearly mimics the active suspension system behavior. And more importantly, the cost of this system is a lot less than the active suspension system. 


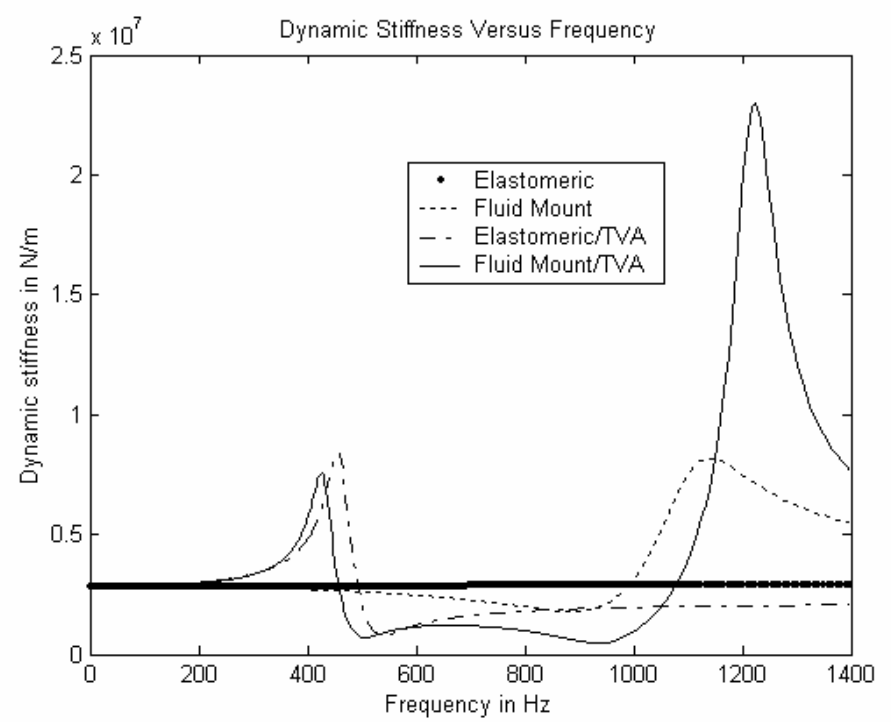

Fig. 16. Dynamic stiffness comparison of different vibration isolation.

\section{References}

[1] L.R. Miller and M. Ahmadian, Active Mounts - A Discussion of Future Technological Trends, in Proceedings of Internoise-92, Toronto, Canada, July 1992.

[2] M. Clark, Hydraulic Engine Mount Isolation, SAE\# 851650, 1985.

[3] P.E. Corcoran and G.H. Ticks, Hydraulic Engine Mounts Characteristics, SAE\# 840407, 1984.

[4] W.C. Flower, Understanding Hydraulic Mounts for Improved Vehicle Noise, Vibration and Ride Qualities, SAE\# 850975, 1985.

[5] N. Vahdati, A Detailed Mechanical Model of a Double Pumper Fluid Mount, in ASME Journal of Vibration and Acoustics 120(2) (April 1998), 361-370.

[6] P.L. Graf and R. Shoureshi, Modeling and Implementation of Semi-Active Hydraulic Engine Mounts, Journal of Dynamic Systems, Measurement, and Control 110 (Dec. 1988).

[7] N. Vahdati and M. Ahmadian, Variable Volumetric Stiffness Fluid Mount Design, Shock and Vibration 11(1) (2004), 21-32.

[8] M. Ahmadian and Y.K. Ahn, Performance analysis of magneto-rheological mounts, Journal of Intelligent Material Systems and Structures 10(3) (March 1999), 248-256.

[9] D. York, X. Wang and F. Gordaninejad, A new MR fluid-elastomer vibration isolator, Journal of Intelligent Material Systems and Structures 18(12) (December 2007), 1221-1225.

[10] J.D. Carlson, M.R. Jolly, MR fluid, foam and elastomer devices, Mechatronics 10(4-5) (June-Aug. 2000), 555-569.

[11] L.R. Miller, M. Ahmadian, C.M. Nobles and D.A. Swanson, Modelling and Performance of an Experimental Active Vibration Isolator, Journal of Vibration and Acoustics 117(3A) (July 1995), 272-278.

[12] P. Rowhani, Controlled Mounts for Vibration Attenuation in Aircraft, M.S. Thesis, University of California, Davis, 1990.

[13] S.S. Rao, Mechanical Vibrations, 2nd edition, Addison-Wesley Publishing Company, Massachusetts, 1990, $465-468$.

[14] W.T. Thomson, Theory of Vibration with Applications, 4th edition, Prentice Hall, New Jersey, 1993, $150-154$.

[15] R.C. Rosenberg and D.C. Karnopp, Introduction to Physical System Dynamics, McGraw-Hill Book Company, New York, 1983. 

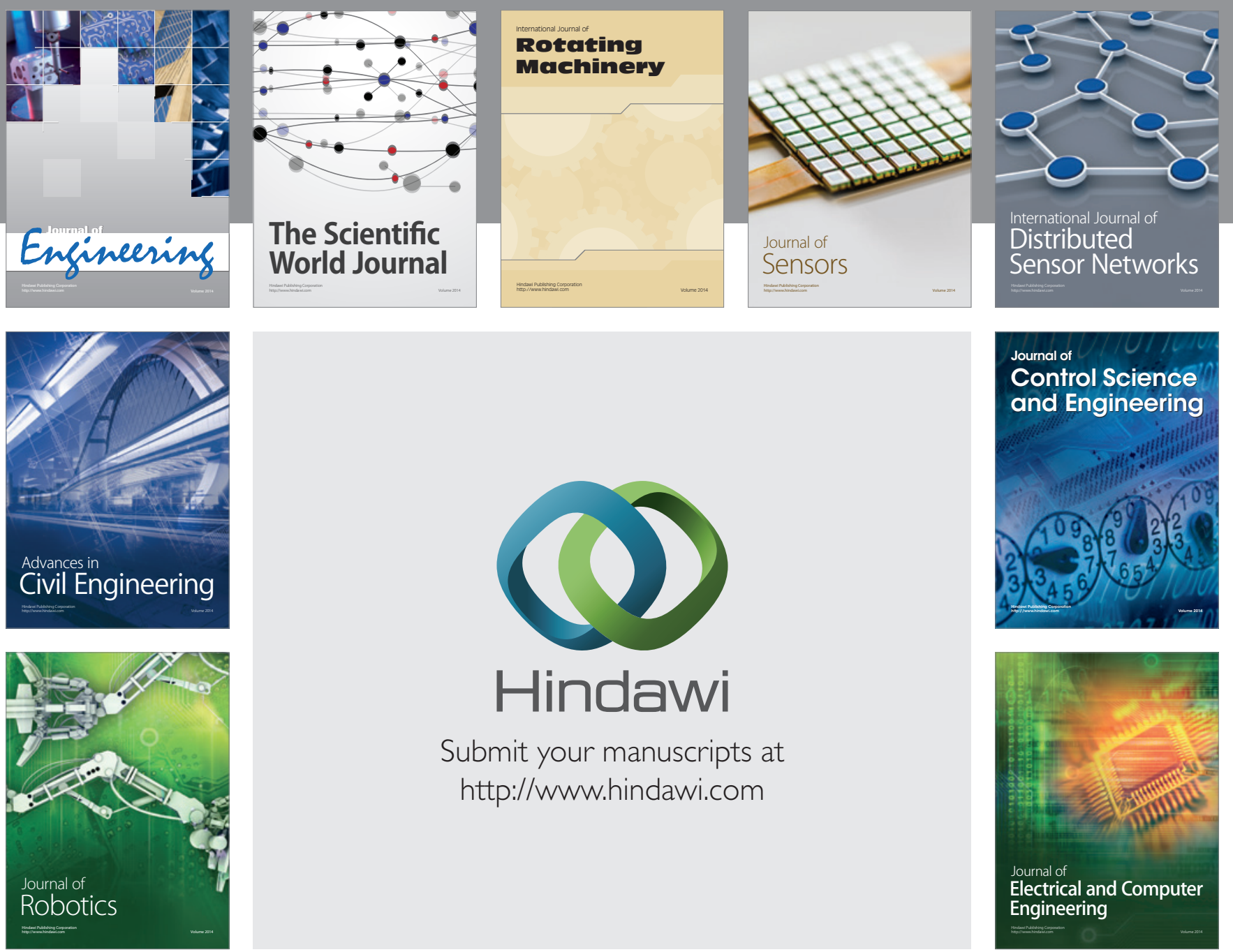

Submit your manuscripts at

http://www.hindawi.com
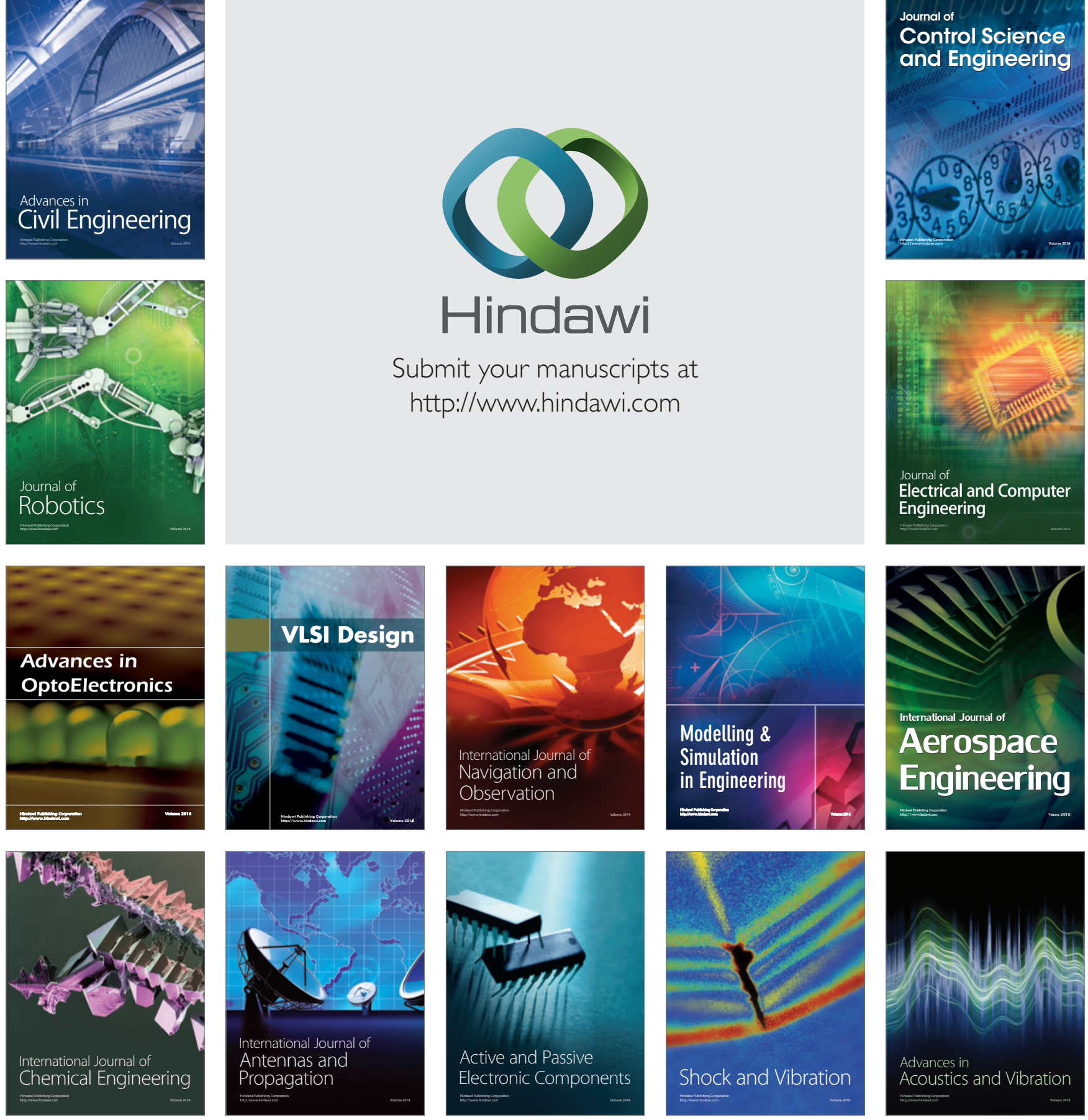